\title{
THE EFFECTS OF POROSITY AND ANGLE OF INCLINATION ON THE DEFLECTION OF FLUID FLOW IN POROUS MEDIA
}

\author{
O. I. POPOOLA, J. A. ADEGOKE AND O. O. ALABI
}

(Received 12, December 2008; Revision Accepted 14, April 2009)

ABSTRACT

The movement of contaminated fluid from a solid waste landfill into a portable water aquifer located beneath is an example of unwanted underground flow. With the problem of limited portion of land available for building construction in the cities, coupled with the rise in price of good and accessible land, there is a need for quick and urgent solutions to environmental pollution that may be resulted from this problem. In this research, a laboratory setup consisting of a big transparent cylindrical pipe $108.5 \mathrm{~cm}$ long with radius $2.23 \mathrm{~cm}$ was used as inlet pipe and five small equal transparent cylindrical pipes with radii $0.03 \mathrm{~cm}$ were used as outlets, which were joined to the circular plastic plate on the top of the inlet pipe at different angles ranged from $0^{\circ}$ to $90^{\circ}$ from a normal point. The inlet pipe and outlets pipes were filled with samples of soil of different porosities and titled at different angles of inclination. The volume of water discharged was measured directly with measuring cylinder from the set-up in each case. The volumetric flow rate and volume flux were computed from the values of volume discharged. These were done in order to determine how the arrangement of porous material of different porosities with a particular angle of inclination can influence the deflection of fluid flow from its linear direction. This is sequel to its practical applications in designing a construction with a cross-section of soils in deflecting contaminated fluid from septic tank to different directions from the source of water within the same small portion of land. It was observed that angle of inclination does not have a significant effect on the deflection of fluid but volume flux increases with increasing angle of inclination. Also, the greater the difference in the porosity of the cross-section of the media in which the fluid is flowing the greater the volume flux. However, the most suitable arrangement of cross-section of soils for deflection of fluid at higher angle from normal is when it flows through a medium of low porosity to that of higher porosity.

KEYWORDS: Porosity, Inclination angle, Volume flux, Deflection, Outlet angle

\section{INTRODUCTION}

The contamination of soil and underground water with mineral oils (hydrocarbon) or mineral oilbased product is among the common negative effects of industrial society (Seitinger and Schindlhauer, 1994). Contamination comes from a variety of source, ranging from underground petrol tank at filling stations to nuclear weapons facilities. Industrial plants and garbage dump can also cause environmental problems (Breadhoeft, 1996).

Control of the water content, control of the movement of water, and prevention of damaged caused by the movement of water in soils are vital aspects of soil engineering (Sower, 1970). Soil mass through which seepage occur is man-made, like septic tank or sewage disposal facility, the permeability can be reduced by the proper selecting materials, for example, mixing a small amount of clay with the sand (Protective filter) used for construction can reduce the permeability greatly (Sower, 1970). The study of seepage patterns in crosssection with soils of more than one permeability is one of the most worthwhile and rewarding applications especially in selecting a protective filter or seepage control in man-made constructions (Popoola, et al, 2008).
The permeability is the most important physical property of a porous medium, which is a measure of the ability of a material to transmit fluid through it. The application of Darcy's law enables hydraulic conductivity to be determined, from which permeability can be computed by using Hubert King relation (Domenico and Schwartz, 2000). The flow of fluid in porous media is govern by Darcy' law. This law holds when the water particles move in a smooth, orderly procession in the direction of flow that is laminar (Barer et al, 1972). The porosity of a porous medium depends on grain size distribution, state of grain aggregate or arrangement, shape of the grains, continuity, and tortosity of the pores (Brain and Robert, 2002). The determination of seepage velocity of fluid in the porous media which is one of the major parameter in applications of Darcy's law in solving environmental problems depends strongly on the porosities of the media.

The study is to improve on the work made so far by Darcy. The objectives are to investigate how volume flow rate and volume flux of fluid are affected when it flows through porous media of different porosities with respect to their varying angles of inclination, which are important parameters in knowing the ability of deflecting the fluid flow to higher angles from normal direction When it flows through cross-section of soil different

O. I. Popoola, Department of Physics, University of Ibadan, Ibadan, Nigeria.

J. A. Adegoke, Department of Mathematical and Physical Sciences, College of Sciences, Engineering and Technology, Osun State University, P.M.B. 4494, Osogbo, Osun State, Nigeria.

O. O. Alabi, Department of Mathematical and Physical Sciences, College of Sciences, Engineering and Technology, Osun State University, P.M.B. 4494, Osogbo, Osun State, Nigeria. 
porosities. These are necessary for designing a seepage control in such a way that septic tank can be constructed safely within the same portion of land, along with the borehole or well without the source of water being contaminated.

\section{THEORY}

Hydraulic conductivity $k$, is the specific discharge per unit hydraulic gradient. It expresses the ease with which a fluid is transported through void space. It depends on the solid matrix and fluid properties. The permeability $k$, of a porous medium is its fluid capacity for transmitting a fluid under the influence of a hydraulic gradient (Sherwani, 1978). It depends solely on the geometrical structure of the material, that is, porosity, grain size distribution, turtosity and connectivity.

Fluid flow through porous material of permeability $k$, by Darcy is generally written as:

$$
V_{S}=-\frac{K}{\mu}(P-\rho g) \text { (Frick and Taylor, 1978) }
$$

Which can be expressed as

$$
V_{S}=-\frac{K}{\mu}\left(\frac{d p}{d s}-\rho g \frac{d z}{d s}\right)
$$

Where

$S=\quad$ Distance in the direction of flow, always positive

$V_{s}=\quad$ Volume flux across a unit area of the porous medium is unit time.

$Z=\quad$ Vertical coordinate, considered downward;

$\rho=\quad$ Density of the fluid

$g=\quad$ Acceleration of gravity;

$\frac{\mathrm{dp}}{\mathrm{ds}}=$ Pressure gradient along $\mathrm{s}$ at the point to point to what $\mathrm{V}_{\mathrm{s}}$ refers;

$\mu=\quad$ Viscosity of the fluid;

$k=\quad$ Permeability of the medium;

$\frac{\mathrm{d} z}{\mathrm{ds}}=\operatorname{Sin} \theta$, where $\theta$ is the angle betweens and the horizontal $V_{s}$

Equation 2 can be expressed further as follows:

$$
\begin{gathered}
\mathrm{V}_{\mathrm{s}}=-\frac{\mathrm{K}}{\mu}\left(\rho \mathrm{g} \frac{\mathrm{dp}}{\mathrm{ds}}-\frac{\mathrm{dz}}{\mathrm{ds}}\right) \\
\frac{\mathrm{V}_{\mathrm{s}} \mu}{K}=\left(\rho \mathrm{g} \frac{\mathrm{dz}}{\mathrm{ds}}-\frac{\mathrm{dp}}{\mathrm{ds}}\right) \\
\frac{\mathrm{dz}}{\mathrm{ds}}=\operatorname{Sin} \theta
\end{gathered}
$$

Integrating both sides

$$
\begin{aligned}
& \left\{\frac{V_{S} \mu}{K}-\rho g \sin \theta\right\} \frac{d s}{d p}=\frac{P_{2}}{P_{1}} \\
& \left\{\frac{\mathrm{V}_{\mathrm{S}} \mu}{\mathrm{K}}-\rho g \sin \theta\right\} \mathrm{s}=\mathrm{P}_{1}-\mathrm{P}_{2}=\mathrm{P} \\
& \frac{\mathrm{V}_{\mathrm{S}} \mu}{K}=\frac{\mathrm{P}}{\mathrm{S}}+\rho \mathrm{g} \sin \theta
\end{aligned}
$$

If a porous medium is completely saturated with an incompressible fluid and is vertical (Fig 1 and fig 2) $\frac{d z}{d s}=\operatorname{Sin} 90^{0} \quad\left(\theta=90^{\circ}, \sin 90^{\circ}=1\right)$

Then Equation 10 reduces to

$$
\begin{aligned}
& \frac{\mathrm{V}_{\mathrm{s}} \mu}{\mathrm{K}}=\frac{\mathrm{P}}{\mathrm{S}}+\rho \mathrm{g} \\
& \mathrm{V}_{\mathrm{s}}=\frac{\mathrm{K}}{\mu}\left\{\frac{\mathrm{P}}{\mathrm{S}}+\rho \mathrm{g}\right\}
\end{aligned}
$$




$$
\begin{gathered}
V_{S}=\frac{K}{\mu}\left\{\frac{\rho g h}{S}+\rho \rho g\right\} \\
\mathrm{V}_{\mathrm{S}}=\frac{\rho g}{\mu} \mathrm{k}\left\{\frac{\mathrm{h}}{\mathrm{L}}+\rho \mathrm{g}\right\}
\end{gathered}
$$

But

Where

$$
\mathrm{K}=\frac{\rho \mathrm{g}}{\mu} \mathrm{K} \text { (Domenico et al; 2000) }
$$

$K=$ Hydraulic conduct $\left(\mathrm{ms}^{-1}\right)$;

$k=$ Permeability $\left(\mathrm{m}^{2}\right)$;

$\mu=$ Viscosity of fluid $\left(\mathrm{Nsm}^{-2}\right)$;

$\rho=$ Density of fluid $\left(\mathrm{kgm}^{-3}\right)$ and

$\mu / \rho=$ Kinematics viscosity (for water) $=1 \times 10^{-6} \mathrm{~m}^{2} \mathrm{~s}^{-1}$
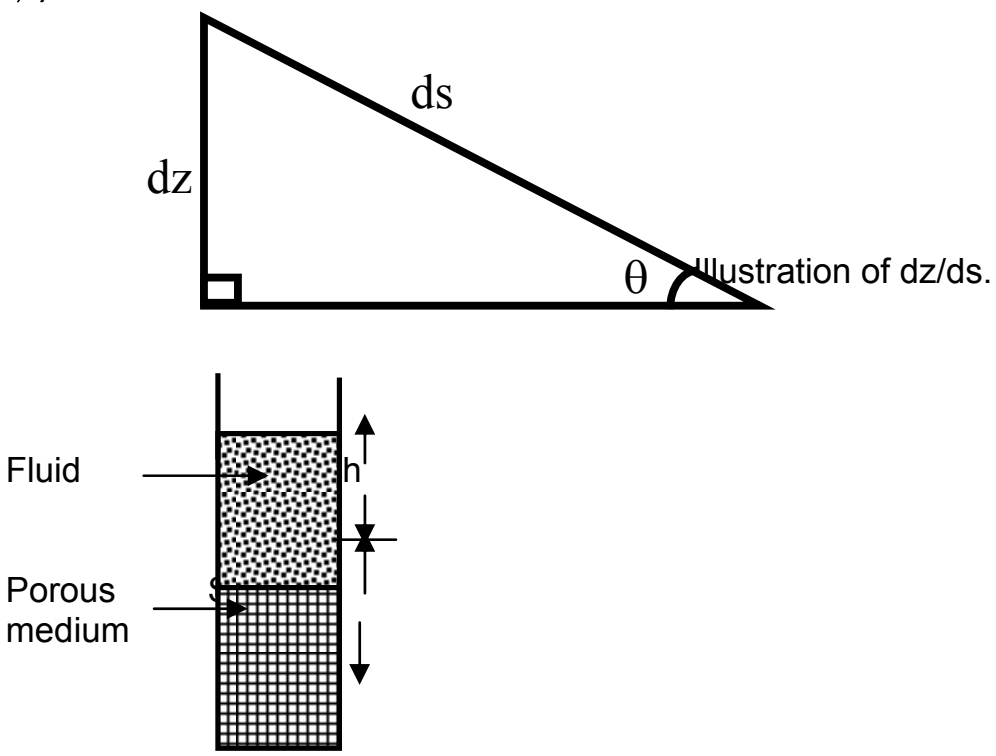

Fig. 2: When $\theta=90^{\circ}$ with horizontal (vertical flow).

The hydraulic conductivity contains properties of both medium and fluid with units $\mathrm{ms}^{-1}$ and characterizes the capacity of a medium to transmit water, whereas the permeability with units $\mathrm{m}^{2}$ characterizes the capacity of the medium to transmit any fluid. The two properties are related by Equ. (15).

By using equ. 15 in equ. 14 becomes

$$
\begin{aligned}
& \mathrm{V}_{\mathrm{S}}=\mathrm{k}\left\{\frac{\mathrm{h}}{\mathrm{L}}+1\right\} \\
& \mathrm{V}_{\mathrm{S}}=\mathrm{q}=\frac{\mathrm{Q}}{\mathrm{A}}=\mathrm{k}\left\{\frac{\mathrm{h}}{\mathrm{L}}+1\right\} \quad \text { (Jacob and Arnold, 1990) }
\end{aligned}
$$

Where

$Q=$ Volumetric flow rate $\left(\mathrm{m}^{3} \mathrm{~s}^{-1}\right)$

$A=$ Average cross-sectional area perpendicular to the line of flow $\left(\mathrm{m}^{2}\right)$;

$q=$ Volume flux $\left(\mathrm{ms}^{-1}\right)$;

$h=$ Head constant (or hydraulic head) (m); and

$L=$ Flow path length of sample $(\mathrm{m})$.

Thus, equ. 17 can be written in simple form as

Where

$$
\begin{array}{ll}
\mathrm{q}=\mathrm{k}\left\{\frac{\mathrm{h}}{\mathrm{L}}+i\right\} & \begin{array}{l}
\text { (Ghildyal and Tripath, 1987) } \\
q=K i
\end{array} \\
\text { or }
\end{array}
$$

$$
i=\left\{\frac{\mathrm{h}}{\mathrm{L}}+1\right\}=\text { Hydraulic gradient. }
$$

while the volume flux $\mathrm{q}$, is the volume of water flowing across a unit area of the porous medium in a unit of time along the flow path. It has the units velocity but it is not the velocity of the water in the pores because the matrix takes up some of the flow area. The average pore water velocity is termed the seepage velocity, $v$ and is given as: 
Where

$$
V=\frac{\mathrm{Q}}{\mathrm{A} \phi}=\frac{\mathrm{q}}{\phi} \quad \text { (Jacob and Arnold, 1990) }
$$

$$
\begin{gathered}
V=\text { seepage velocity }\left(\mathrm{ms}^{-1}\right), \\
q=\text { volume flux }\left(\mathrm{ms}^{-1}\right) \text { and } \\
\phi=\text { porosity of the media. }
\end{gathered}
$$

The maximum pure velocity is a function of the pore geometry and cannot be easily predicted except for simple shapes. However, it can be determined in the laboratory by volumetric method.

\section{Flow through sections of more than one Permeability \\ In some instances, a great deal can be learned} by studying seepage patterns in cross sections with soils of more than one permeability, such studies have revealed important shortcomings in some commonly accepted beliefs about seepage and drainage (Cedergreen, 1976).

When water flows across a boundary between dissimilar soils, the flow line bend much in the way that light ray are deflected in passing from air into water or from air into glass. (Cedergreen, 1976). The law of conservation of energy forces all natural phenomena to take the line of least resistance. Thus, when water flows from a soil of high permeability into a material of lower permeability, the pattern develops in such a way that the flow remains in the more permeable material for the greatest possible distance. Likewise, if the flow is from a material of low permeability into one of higher permeability, it deflects as soon as possible into the material of higher permeability (Cedergreen, 1976). To conserve energy water seeks the easiest paths to travel.

Another way of looking at the behavior of seepage in sections with more than one permeability is the concept that, other factors being equal, the higher the permeability, the smaller the area referred to pass a given volume of water conversely, the lower the permeability, the greater the area required

In relation to the amount of energy needed to force water through porous media, the higher the permeability, the lower the energy needed and vice versa. In seepage the rate of loss of energy is measured by the steepness of the hydraulic gradient, steep hydraulic gradient should be expected in the zones of low permeability and flats gradients, in zones of high permeability. (Cedergreen, 1976).

\section{Deflection of Flow Lines Across Boundaries Between Soils of Different Permeabilities}

The way flow lines deflect when they cross the boundaries between soil of different permeabilities in shown in fig. 3 . the flow lines bend to confirm to the following relationship.

$$
\frac{\operatorname{Tan} \beta}{\operatorname{Tan} \alpha}=\frac{k_{1}}{k_{2}}
$$

Simultaneously, the areas formed by the intersecting line either elongate or shorten, depending on the ratio of the two permeabilities, according to the following relationship;

$$
\frac{c}{d}=\frac{k_{2}}{k_{1}}
$$
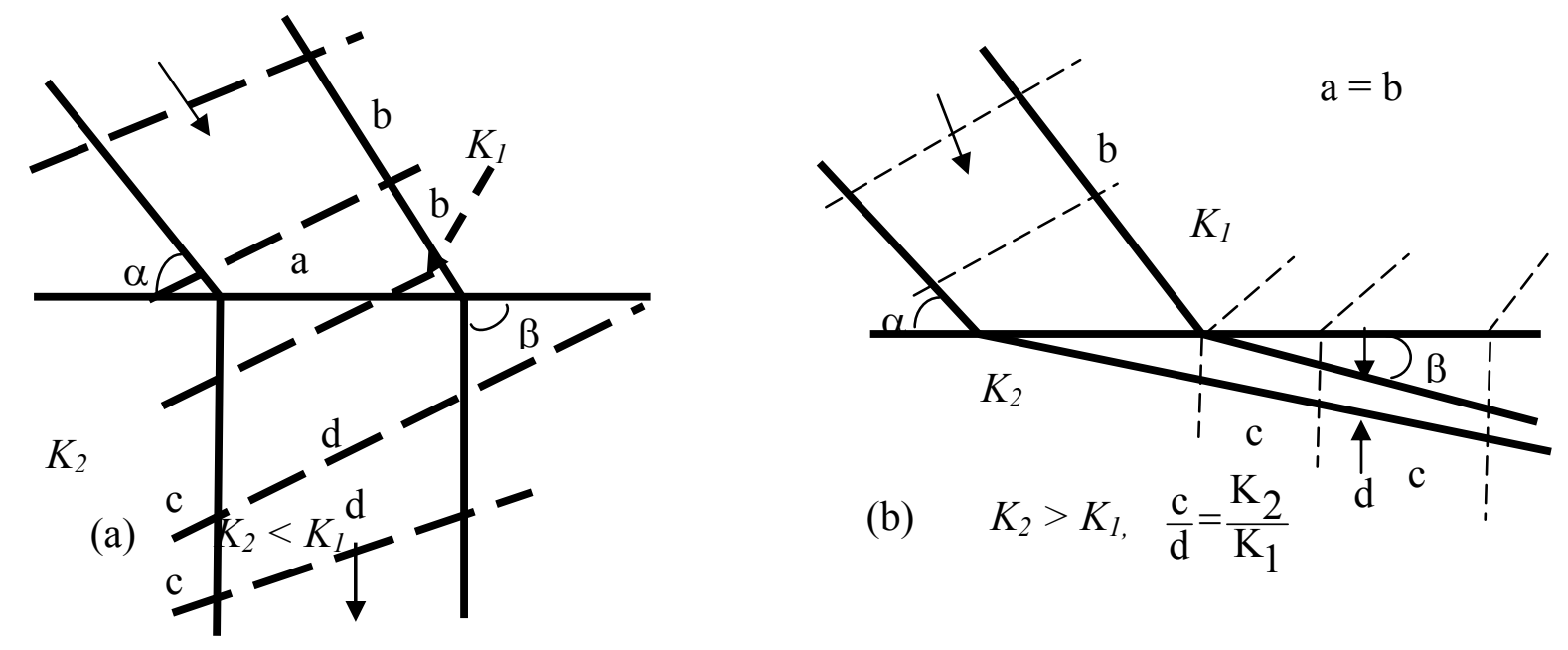

Fig 3: Transfer conditions at boundaries between soils of different perm abilities. (After A. Casagrande, seepage Through Dams, 1937) 
In Fig $3 a$ the second permeability is lower than the first hence shortened rectangles are formed in the second. In Fig. 3b second permeability is greater than the first, so elongated rectangles form in the second materials. The deflection relationship expressed by Eqn. 21 should be in mind, however, the change is the shapes of areas as expressed by Eqn. 22 is extremely useful, as it provides an exact check of the accuracy of flow nets for sections with more than one permeability.

A similar explanation was given by Eagleman and Jamison in 1962 for soil layers of different texture. The illustration given was that if a finer textured soil layer overlying a coarser-textured layer (Fig .4), it.
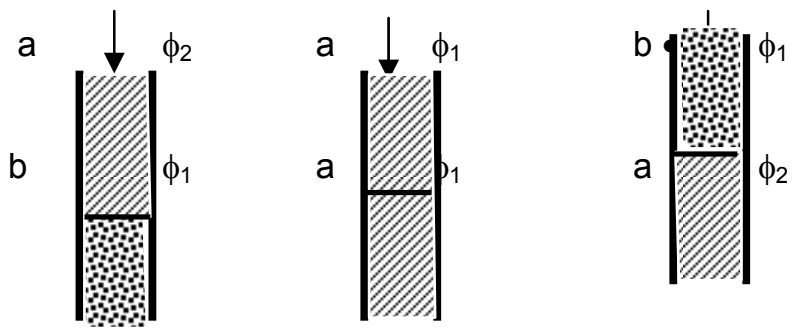

Fig 4: Case A. Fig. 5: Case B. Fig. 6: Case C.

\section{MATERIALS AND METHODS}

\section{Sample Preparation}

Sand samples were collected from the riverbed of Rivers Zik and Ajibode within the University of Ibadan. Sizeable quantities of these samples were washed and rinsed in order to remove organic particles and unwanted grains and then brought to the laboratory. Thereafter, the sand samples were sun dried and later placed in an oven for 30minutes at temperature of $120^{\circ} \mathrm{C}$. After, the samples were allowed to cool down, the stony particles and pepples were removed. Five different sieves of sizes $63,150,212,300$ and $425 \mu \mathrm{m}$ were used to sieve the available sand samples in order to obtain samples of different grain sizes.

\section{Determination of Porosity}

The porosity of each sample was determined by volumetric approach. In the laboratory measurement of porosity, it is necessary to determine only two basic parameters (bulk volume and grain volume).

Bulk volume $=$ grain volume + pore volume

Total porosity, $\varphi=\frac{\text { Bulk volume - Grain volume }}{\text { Bulk volume }}$

$$
\varphi=\frac{\text { Pore volume }}{\text { Bulk volume }}
$$

In this research, bulk and grain or matrix volume were determined volumetrically by measured $3 \mathrm{ml}$ of dried sand sample using a $10 \mathrm{ml}$ measuring cylinder. It was ensured that the measuring cylinder was tapped with a solid object and the sand inside get re-arranged and compacted before the value of the volume was particularly if the boundary between the two layer is fairly sharp, will hold more water against drainage than if its underlain by material of its own texture (Fig. 5), or a finer-textured layer (Fig. 6). This is very noticeable if the coarser-textured layer is a sand, for there will be a sudden change of capillary conductivity at this junction. When the water lost its interstitial water, so water will only be able to leak out from the finer-texture soil very slowly because of the low capillary conductivity of the sand. It is evident form above explanation that the volume of water discharge can be affected by changes of texture vis-à-vis porosity in the profile below

$$
\begin{aligned}
& a=\text { Coarser-textured soil layer } \\
& b=\text { finer-textured soil } \\
& \phi_{1}=\text { Porosity of sample } a \\
& \phi_{2}=\text { Porosity of sample b } \\
& \phi_{1}>\phi_{2}
\end{aligned}
$$

recorded. This is necessary in order to maintain steady volume. A similar measuring cylinder was half-filled with water and the volume was noted. The sand was then poured into the water and the final volume of the components of the cylinder (water and sand) is recorded.

Porosity can be determined as follows:

$$
\begin{array}{ll}
\text { Volume of sand (bulk volume) } & =A(\mathrm{~mL}) \\
\text { Volume of water } & =B(\mathrm{~mL})
\end{array}
$$

Volume of mixture of water and sand $=\mathrm{C}(\mathrm{mL})$

Therefore total porosity, $\varphi=\frac{\text { Pore volume }}{\text { Bulk volume }}$

$$
=\varphi=\frac{(A+B)-C}{A}(m L)
$$

\section{Determination of Hydraulic Conductivity and Permeability}

In an experimental set up in the laboratory, volume flux $q$, for each sample at different hydraulic gradients was determined. A saturated sand sample was transferred to the transparent cylindrical tube of cross-sectional area $2.69 \times 10^{-4} \mathrm{~m}^{2}$ (Fig.5). To ascertain uniform compaction throughout the sample, the screened end was blocked so as to prevent the water passing through when the sample was being transferred. A continuous steady supply of water was fed through the sand sample samples of length $L$ and at height $h$ a hole was drilled, this enabled the height to be maintained, as excess water got drained through on overflow arrangement. The volume of water discharged $Q$, through the sample for a period of $60 \mathrm{sec}$ after steady state has been attained at constant head was measured by measuring cylinder. It must be noted that the length $L$ was varied in order to obtain different hydraulic 
gradients. Measurements were made at hydraulic gradients of $i=1.875,3.750,7.500,15.000$ and 30.000, for each sample. The results of there experiment were used to prepare plots of volume flux against hydraulic gradient and the slop of the graph is hydraulic conductivity. The permeability was then computed by using Eqn. 15.

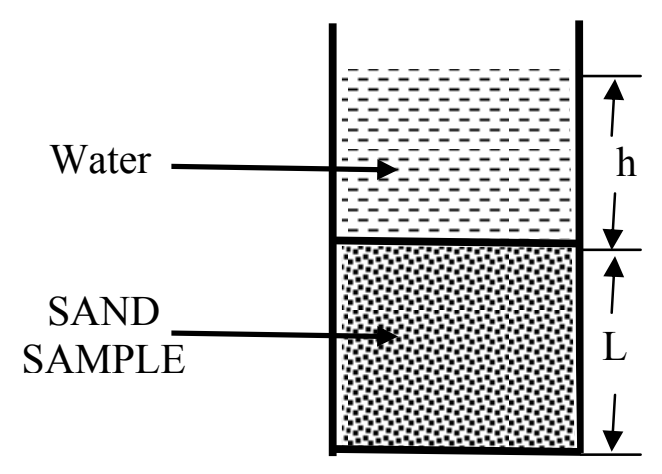

Fig. 5: Sand model for vertical flow head $h$ (Jacob, 2001)

\section{Determination of Volume Flux at Different Angles of} Inclination

The experimental set-up consisted of a big transparent cylindrical pipe $108.5 \mathrm{~cm}$ long with radius $2.23 \mathrm{~cm}$ as inlet pipe and five small equal transparent cylindrical pipes of length with radii $0.3 \mathrm{~cm}$ as outlets (Fig. 6). Each of the outlet pipes was joined to the centre of the circular plastic plate on the top of the inlet pipe at different angles $\theta$ of $0^{\circ}, 20^{\circ}, 50^{\circ}, 70^{\circ}$ and $90^{\circ}$ from the point normal or line. To serve as control experiment, water was allowed to flow through the empty inlet pipe and outlet pipe for a period of 60 sec and the discharged volume of water at each outlet was collected and measured with measuring cylinder. This was done at different tilting angle or angle of inclination $\theta$ of $0^{0}, 5^{\circ}$, $10^{\circ}, 15^{\circ}$ and $20^{\circ}$. Thereafter, the inlet pipe and outlet pipes were filled with the same sample at a time and the volume of water discharged through this sample in each outlet was measured for different angle of inclination $\alpha$. This was repeated for other samples. Then, all the fire outlets were filled with the sample $A$ of the lowest porosity while the inlet pipe was filled with another sample of different porosity. The volume of water discharge from each outlet was measured. This was done at different angle of inclination $\alpha$ in order to know effect of angle of inclination on fluid flow rate for each sample. The sample in the inlet pipe was later changed in turn and the volume of water discharged from the outlets in different cases were collected and measured directly with measuring cylinder. The volume flux $q\left(\mathrm{~ms}^{-}\right.$ ${ }^{1}$ ) or specific discharge was then computed from the volumetric flow rate $Q\left(\mathrm{~m}^{3} \mathrm{~s}^{-1}\right)$ by dividing it with the cross-sectional area $2.83 \times 10^{-5} \mathrm{~m}^{2}$ of the outlet pipe.
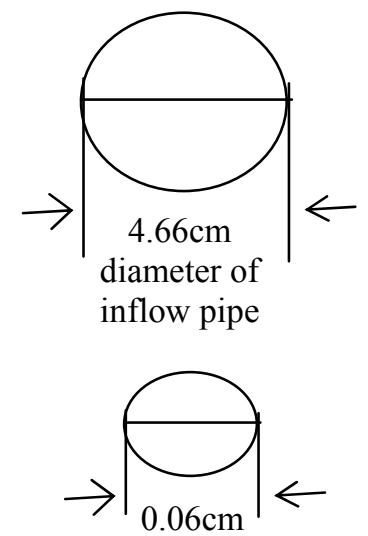

diameter of outflow pipe

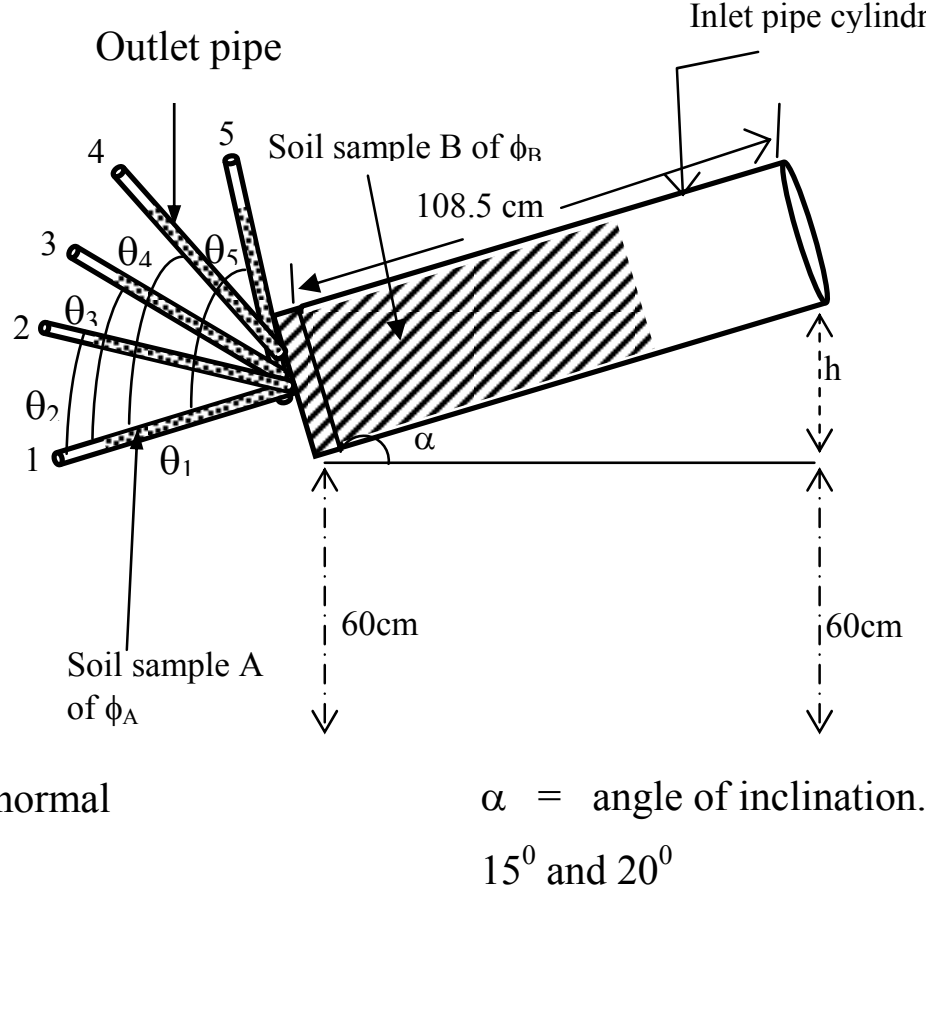

Outlet pipe

Note:

As $h$ is varied $\alpha$ will be varied $\alpha=$ angle of inclination. $\alpha=0^{0}, 5^{0}, 10^{\circ}$, $15^{0}$ and $20^{0}$

$$
\begin{aligned}
& \theta_{1}=0^{0} \text { to the normal } \\
& \theta_{2}=20^{0} \\
& \theta_{3}=50^{0} \\
& \theta_{4}=70^{0} \\
& \theta_{5}=90^{0}
\end{aligned}
$$

Fig. 6: Experimental set up to determine volume flux at different angles of inclination. 
Table 1: Grain size, Porosity and Permeability of the samples.

\begin{tabular}{ccll}
\hline Sample & Grain size $(\mu \mathrm{m})$ & Porosity & Permeability $\left(\mathrm{m}^{2}\right)$ \\
\hline A & 63 & $0.250 \pm 0.010$ & $0.47 \times 10^{-11}$ \\
B & 150 & $0.333 \pm 0.020$ & $1.06 \times 10^{-11}$ \\
C & 300 & $0.364 \pm 0.001$ & $1.16 \times 10^{-11}$ \\
D & 425 & $0.420 \pm 0.001$ & $3.23 \times 10^{-11}$ \\
\hline
\end{tabular}

Table 2: Volume of water discharge from outlet pipe at different angles of inclination $\alpha$.

\begin{tabular}{cccccccc}
\hline $\begin{array}{c}\text { Angle of Inclination } \\
\alpha \text { (degree) }\end{array}$ & $\begin{array}{c}\text { Outlet 1 } \\
(\mathrm{mL})\end{array}$ & $\begin{array}{c}\text { Outlet 2 } \\
(\mathrm{mL})\end{array}$ & $\begin{array}{c}\text { Outlet 3 } \\
(\mathrm{mL})\end{array}$ & $\begin{array}{c}\text { Outlet 4 } \\
(\mathrm{mL})\end{array}$ & $\begin{array}{c}\text { Outlet 5 } \\
(\mathrm{mL})\end{array}$ & $\begin{array}{c}\text { Total } \\
(\mathrm{mL})\end{array}$ \\
\hline Case I & 0 & 0 & 0 & 0 & 0 & 0 & 0 \\
& 5 & 22.2 & 13.0 & 14.0 & 32.0 & 0.0 & 81.2 \\
& 10 & 31.2 & 24.2 & 26.0 & 54.2 & 0.0 & 135.6 \\
& 15 & 65.4 & 32.6 & 22.2 & 17.4 & 0.0 & 137.6 \\
& 20 & 88.0 & 69.0 & 21.4 & 9.2 & 0.0 & 187.6
\end{tabular}

Case II

Case III

$\begin{array}{lllllll}0 & 0 & 0 & 0 & 0 & 0 & 0 \\ 5 & 6.4 & 1.8 & 0.6 & 0 & 0 & 8.8 \\ 10 & 8.0 & 6.2 & 2.2 & 0 & 0 & 16.4 \\ 15 & 12.0 & 6.8 & 2.6 & 0.4 & 0.2 & 22 \\ 20 & 15.0 & 12.2 & 4.8 & 0.8 & 0.6 & 33.4\end{array}$

$\begin{array}{llllllll}\text { Case IV } & & & & 0 & 0 & 0 & 0 \\ & 5 & 0 & 0 & 2.4 & 1.0 & 0.8 & 26.2 \\ & 10 & 21.6 & 15.2 & 8.4 & 6.4 & 3.4 & 55.0 \\ & 15 & 32.6 & 26.2 & 15.0 & 6.8 & 3.8 & 84.4 \\ & 20 & 38.2 & 42.4 & 16.2 & 7.2 & 4.0 & 108\end{array}$

Case V

$\begin{array}{lll}0 & 0 & 0 \\ 5 & 8.4 & 2.2 \\ 10 & 12.0 & 8.0 \\ 15 & 17.0 & 14.0 \\ 20 & 24.0 & 23.4\end{array}$

$\begin{array}{llll}0 & 0 & 0 & 0 \\ 1.6 & 0 & 0 & 12.2 \\ 6.8 & 3.8 & 2.8 & 33.4 \\ 8.0 & 4.2 & 3.2 & 46.4 \\ 12.8 & 5.8 & 4.6 & 70.6 \\ & & & \\ 0 & 0 & 0 & 0 \\ 2.4 & 1.0 & 0.8 & 26.2 \\ 8.4 & 6.4 & 3.4 & 55.0 \\ 15.0 & 6.8 & 3.8 & 84.4 \\ 16.2 & 7.2 & 4.0 & 108\end{array}$

\begin{tabular}{|c|c|c|c|c|c|c|c|}
\hline & & & & & & & \\
\hline & 0 & 0 & 0 & 0 & 0 & 0 & 0 \\
\hline & 5 & 17.2 & 5.8 & 2.8 & 1.8 & 1.4 & 29 \\
\hline & 10 & 22.0 & 16.0 & 9.2 & 8.2 & 3.8 & 59.2 \\
\hline & 15 & 32.8 & 28.2 & 18.0 & 8.8 & 4.6 & 92.4 \\
\hline & 20 & 40.4 & 52.0 & 17.0 & 9.8 & 5.2 & 124.4 \\
\hline \multicolumn{8}{|c|}{ Case VI } \\
\hline & 0 & 0 & 0 & 0 & 0 & 0 & 0 \\
\hline & 5 & 6.8 & 2.8 & 0.8 & 0.0 & 0 & 10.4 \\
\hline & 10 & 8.2 & 6.4 & 3.2 & 0.0 & 0 & 17.8 \\
\hline & 15 & 8.8 & 8.2 & 6.0 & 1.8 & 0 & 24.8 \\
\hline & 20 & 19.4 & 18.6 & 7.6 & 4.2 & 0 & 49.8 \\
\hline \multicolumn{8}{|c|}{ Case VII } \\
\hline & 0 & 0 & 0 & 0 & 0 & 0 & 0 \\
\hline & 5 & 10.6 & 3.2 & 1.6 & 0.0 & 0 & 15.4 \\
\hline & 10 & 15.4 & 7.8 & 4.8 & 0.2 & 0 & 28.2 \\
\hline & 15 & 21.2 & 12.6 & 10.4 & 2.2 & 0 & 46.4 \\
\hline & 20 & 26.2 & 21.6 & 12.4 & 5.2 & 0 & 65.4 \\
\hline \multicolumn{8}{|c|}{ Case VIII } \\
\hline & 0 & 0 & 0 & 0 & 0 & 0 & 0 \\
\hline & 5 & 13.4 & 4.0 & 2.2 & 0.0 & 0 & 19.6 \\
\hline & 10 & 18.8 & 9.0 & 7.4 & 0.4 & 0 & 35.6 \\
\hline & 15 & 28.6 & 14.6 & 12.0 & 4.2 & 0 & 59.4 \\
\hline & 20 & 30.4 & 23.4 & 14.2 & 6.4 & 0 & 74.4 \\
\hline
\end{tabular}

Case IX

$\begin{array}{lllllll}0 & 0 & 0 & 0 & 0 & 0 & 0 \\ 5 & 0.0 & 1.4 & 1.6 & 1.0 & 0.2 & 4.0 \\ 10 & 0.2 & 3.6 & 4.8 & 1.2 & 0.4 & 10.2 \\ 15 & 0.6 & 4.2 & 7.4 & 2.4 & 0.8 & 15.4\end{array}$




\begin{tabular}{llllllll} 
Case X & 20 & 0.8 & 2.8 & 8.8 & 5.2 & 1.2 & 18.8 \\
& 0 & 0 & 0 & 0 & 0 & 0 & 0 \\
& 5 & 0.4 & 1.2 & 1.8 & 1.8 & 0.6 & 5.8 \\
& 10 & 0.6 & 1.4 & 5.0 & 4.8 & 0.8 & 12.6 \\
Case XI & 15 & 1.0 & 1.4 & 7.8 & 7.6 & 1.2 & 19.0 \\
& 20 & 1.2 & 1.2 & 9.2 & 8.4 & 2.4 & 22.4 \\
& 0 & 0 & 0 & 0 & 0 & 0 & 0 \\
& 5 & 0.8 & 1.0 & 2.0 & 2.2 & 1.2 & 7.2 \\
& 10 & 1.6 & 1.6 & 5.2 & 5.8 & 1.6 & 15.8 \\
& 15 & 1.8 & 2.0 & 8.2 & 8.6 & 2.0 & 22.6 \\
\hline
\end{tabular}

Note:

Case I: The inlet pipe and outlet pipes were free of porous material (or empty)

Case II: The inlet pipe and outlet pipes were filled with sample A.

Case III: The inlet pipe and outlet pipes were filled with sample B.

Case IV: The inlet pipe and outlet pipes were filled with sample C.

Case V:The inlet pipe and outlet pipes were filled with sample D.

Case VI: The inlet pipe was filled with sample B and outlets pipes were filled with sample A.

Case VII: The inlet pipe was filled with sample $C$ and outlet pipes were filled with sample $A$.

Case VIII: The inlet pipe was filled with sample $D$ and outlet pipes were filled with sample $A$.

Case IX: The inlet pipe was filled with sample $A$ and outlet pipes were filled with sample B.

Case X:The inlet pipe was filled with sample $A$ and outlet pipes were filled with sample $C$.

Case XI: The inlet pipe was filled with sample $A$ and outlet pipes were filled with sample D.

Outlet 1: $0^{0}$ from the normal

Outlet 2: $20^{\circ}$ from the normal

Outlet 3: $50^{\circ}$ from the normal

Outlet 4: $70^{\circ}$ from the normal

Outlet 5: $90^{\circ}$ from the normal

Table 3: Volumetric flow rate $Q$ at different angles of inclination $\propto$

\begin{tabular}{|c|c|c|c|c|c|c|}
\hline $\begin{array}{l}\text { Angle of } \\
\text { Inclination } \\
\alpha \text { (degree) }\end{array}$ & $\begin{array}{l}\text { Outlet } 1 \\
Q \times 10^{-6} Q \times 10^{-} \\
\left(m^{3} s^{-1}\right)\left(m^{3} s^{-1}\right)\end{array}$ & $\begin{array}{l}\text { Outlet } 2 \\
{ }^{6} \mathrm{Q} \times 10^{-6}\end{array}$ & $\begin{array}{l}\text { Outlet } 3 \\
Q \times 10^{-6} Q \times 10 \\
\left(m^{3} s^{-1}\right)\end{array}$ & $\begin{array}{l}\text { Outlet } \\
-6 \\
\left(\mathrm{~m}^{3} \mathrm{~s}^{-1}\right)\end{array}$ & 4 & $\begin{array}{l}\text { Outlet } 5 \\
\left(\mathrm{~m}^{3} \mathrm{~s}^{-1}\right)\end{array}$ \\
\hline \multicolumn{7}{|l|}{ Case 1} \\
\hline 0 & 0 & 0 & 0 & & 0 & 0 \\
\hline 5 & 0.3700 & 0.2167 & 0.2333 & & 0.5333 & 0 \\
\hline 10 & 0.5200 & 0.4033 & 0.4333 & & 0.9033 & 0 \\
\hline 15 & 0.9000 & 0.5433 & 0.3700 & & 0.2900 & 0 \\
\hline 20 & 1.4667 & 1.1500 & 0.3567 & & 0.1533 & 0 \\
\hline \multicolumn{7}{|l|}{ Case II } \\
\hline 0 & 0 & 0 & 0 & & 0 & 0 \\
\hline 5 & 0.1067 & 0.0300 & 0.0100 & & 0 & 0 \\
\hline 10 & 0.1333 & 0.1033 & 0.0367 & & 0 & 0 \\
\hline 15 & 0.2000 & 0.1133 & 0.0433 & & 0.0067 & 0.033 \\
\hline 20 & 0.2500 & 0.2033 & 0.0800 & & 0.0133 & 0.0100 \\
\hline \multicolumn{7}{|l|}{ Case III } \\
\hline 0 & 0 & 0 & 0 & & 0 & 0 \\
\hline 5 & 0.1400 & 0.0367 & 0.0267 & & 0 & 0 \\
\hline 10 & 0.2000 & 0.1333 & 0.1133 & & 0.0633 & 0.0467 \\
\hline 15 & 0.2833 & 0.2333 & 0.1333 & & 0.0700 & 0.0533 \\
\hline 20 & 0.4000 & 0.3900 & 0.2133 & & 0.0967 & 0.0767 \\
\hline \multicolumn{7}{|l|}{ Case IV } \\
\hline 0 & 0 & 0 & 0 & & 0 & 0 \\
\hline 5 & 0.2800 & 0.0867 & 0.0400 & & 0.0167 & 0.0133 \\
\hline 10 & 0.3600 & 0.2533 & 0.1400 & & 0.1067 & 0.0567 \\
\hline 15 & 0.5433 & 0.4367 & 0.2500 & & 0.1333 & 0.0633 \\
\hline 20 & 0.6366 & 0.7067 & 0.2700 & & 0.1200 & 0.0667 \\
\hline
\end{tabular}


Case V

$\begin{array}{lccccc}0 & 0 & 0 & 0 & 0 & 0 \\ 5 & 0.2867 & 0.0967 & 0.0467 & 0.0300 & 0.0233 \\ 10 & 0.3667 & 0.2667 & 0.5333 & 0.1367 & 0.0633 \\ 15 & 0.5467 & 0.4700 & 0.3000 & 0.1467 & 0.0767 \\ 20 & 0.6733 & 0.8667 & 0.2833 & 0.1633 & 0.0867\end{array}$

Case VI

$\begin{array}{ccc}0 & 0 & 0\end{array}$

$\begin{array}{llll}5 & 0.1133 & 0.0467 & 0.0133\end{array}$

$\begin{array}{llll}10 & 0.1367 & 0.1067 & 0.0533\end{array}$

$15 \quad 0.1467 \quad 0.1367$

0.1000

0.3100

0.1267

Case VII

0.3233

$0 \quad 0$

$5 \quad 0.1767$

0

0.0533

0

0.0267

0.0800

0.1733

0.2100

0.2067

0
0
0

0.0300

0.0700

0.0867

Case VIII

$20 \quad 0.4367$

0.3600

0

0.0667

0.0367

0.1500

0.1233

0.2000

0.2367

0

0.0033

0.0367

0.0867

$$
\begin{aligned}
& 0 \\
& 0 \\
& 0 \\
& 0 \\
& 0
\end{aligned}
$$

0.2433

0

0.0267

0.0800

0.1233

0.1467

\section{0}

0

0.0067

0.0700

0.0667

0
0
0
0
0

Case $X$

$20 \quad 0.0133$

0.0700

0.0467

0
0.0167
0.0200
0.0400
0.0867

0

0.0033

0.0067

0.0133

0.0200

$\begin{array}{clcc}0 & 0 & 0 & \\ 5 & 0.0067 & 0.0200 & 0.0\end{array}$

\section{0}

0.233

0.0300

0

0.300

0

0.0833

0.0800

0.0100

0.1300

0.1267

0.0133

0.0233

0.1533

0.1400

0.0200

0.0200

Case XI

$\begin{array}{ll}0 & 0 \\ 5 & 0.0133 \\ 10 & 0.0267 \\ 15 & 0.0300 \\ 20 & 0.0400\end{array}$

0
0.0167
0.0267
0.0333
0.0433

0
0.0333
0.0867
0.1367
0.1733

0
0.367
0.0967
0.1433
0.1933

0

0.0200

0.0267

\begin{tabular}{|c|c|c|c|c|c|}
\hline $\begin{array}{l}\text { Angle of } \\
\text { Inclination } \\
\alpha \text { (degree) }\end{array}$ & $\begin{array}{ll}\text { Outlet } & 1 \\
q \times 10 & -6 \\
\left(\mathrm{~ms}^{-1}\right) & \end{array}$ & $\begin{array}{l}\text { Outlet 2Outlet } \\
\mathrm{q} \times 10^{-6} \mathrm{q} \times 10^{-6} \\
\left(\mathrm{~ms}^{-1}\right)\end{array}$ & $\begin{array}{l}3 \\
q \times 10^{-6} \\
\left(\mathrm{~ms}^{-1}\right)\end{array}$ & $\begin{array}{l}\text { Outlet } 4 \text { Outlet } 5 \\
\mathrm{q} \times 10^{-6} \\
\qquad\left(\mathrm{~ms}^{-1}\right)\end{array}$ & $\left(\mathrm{ms}^{-1}\right)$ \\
\hline \multicolumn{6}{|l|}{ Case I } \\
\hline 0 & 0 & 0 & 0 & 0 & 0 \\
\hline 5 & 0.1307 & 0.0766 & 0.0824 & 0.1884 & 0 \\
\hline 10 & 0.1837 & 0.1425 & 0.1531 & 0.3192 & 0 \\
\hline 15 & 0.3852 & 0.1920 & 0.1307 & 0.1025 & 0 \\
\hline 20 & 0.5183 & 0.4064 & 0.1260 & 0.0542 & 0 \\
\hline \multicolumn{6}{|l|}{ Case II } \\
\hline 0 & 0 & 0 & 0 & 0 & 0 \\
\hline 5 & 0.0377 & 0.0106 & 0.0035 & 0 & 0 \\
\hline 10 & 0.0471 & 0.0356 & 0.0130 & 0 & 0 \\
\hline 15 & 0.0707 & 0.0400 & 0.0153 & 0.0024 & 0.0012 \\
\hline 20 & 0.0883 & 0.0718 & 0.0283 & 0.0050 & 0.0035 \\
\hline \multicolumn{6}{|l|}{ Case III } \\
\hline 0 & 0 & 0 & 0 & 0 & 0 \\
\hline 5 & 0.0495 & 0.0130 & 0.0094 & 0 & 0 \\
\hline 10 & 0.0707 & 0.0471 & 0.0400 & 0.0224 & 0.0165 \\
\hline
\end{tabular}

0.0333

0.0367

Table 4: Volume flux at different angles of inclination $\alpha$ 
O. I. POPOOLA, J. A. ADEGOKE AND O. O. ALABI

\begin{tabular}{|c|c|c|c|c|c|}
\hline 15 & 0.1001 & 0.0824 & 0.0471 & 0.0247 & 0.0188 \\
\hline 20 & 0.1413 & 0.1378 & 0.0754 & 0.0342 & 0.0271 \\
\hline \multicolumn{6}{|l|}{ Case IV } \\
\hline 0 & 0 & 0 & 0 & 0 & 0 \\
\hline 5 & 0.0989 & 0.0306 & 0.0141 & 0.0059 & 0.0047 \\
\hline 10 & 0.1272 & 0.0895 & 0.0495 & 0.0377 & 0.0200 \\
\hline 15 & 0.1920 & 0.1543 & 0.0883 & 0.0471 & 0.0224 \\
\hline 20 & 0.2249 & 0.2497 & 0.0954 & 0.0424 & 0.0236 \\
\hline \multicolumn{6}{|l|}{ Case V } \\
\hline 0 & 0 & 0 & 0 & 0 & 0 \\
\hline 5 & 0.1013 & 0.0342 & 0.0165 & 0.0106 & 0.0082 \\
\hline 10 & 0.1296 & 0.0942 & 0.1884 & 0.0483 & 0.0224 \\
\hline 15 & 0.1932 & 0.1661 & 0.1060 & 0.0518 & 0.0271 \\
\hline 20 & 0.2379 & 0.3063 & 0.1001 & 0.0577 & 0.0306 \\
\hline \multicolumn{6}{|l|}{ Case VI } \\
\hline 0 & 0 & 0 & 0 & 0 & 0 \\
\hline 5 & 0.0400 & 0.0165 & 0.0047 & 0 & 0 \\
\hline 10 & 0.0483 & 0.0377 & 0.0188 & 0 & 0 \\
\hline 15 & 0.0518 & 0.0483 & 0.0353 & 0.0106 & 0 \\
\hline 20 & 0.1142 & 0.1095 & 0.448 & 0.0247 & 0 \\
\hline \multicolumn{6}{|l|}{ Case VII } \\
\hline 0 & 0 & 0 & 0 & 0 & 0 \\
\hline 5 & 0.0624 & 0.0188 & 0.0094 & 0 & 0 \\
\hline 10 & 0.0907 & 0.0459 & 0.0283 & 0.0012 & 0 \\
\hline 15 & 0.1248 & 0.0742 & 0.0612 & 0.0130 & 0 \\
\hline 20 & 0.1543 & 0.1272 & 0.0730 & 0.0306 & 0 \\
\hline \multicolumn{6}{|l|}{ Case VIII } \\
\hline 0 & 0 & 0 & 0 & 0 & 0 \\
\hline 5 & 0.0789 & 0.0236 & 0.0130 & 0 & 0 \\
\hline 10 & 0.1107 & 0.0530 & 0.0436 & 0.0024 & 0 \\
\hline 15 & 0.1684 & 0.0860 & 0.0707 & 0.0247 & 0 \\
\hline 20 & 0.1790 & 0.1398 & 0.0836 & 0.0836 & 0 \\
\hline \multicolumn{6}{|l|}{ Case IX } \\
\hline 0 & 0 & 0 & 0 & 0 & 0 \\
\hline 5 & 0 & 0.0082 & 0.0094 & 0.0059 & 0.0012 \\
\hline 10 & 0.0012 & 0.0212 & 0.0283 & 0.0071 & 0.0024 \\
\hline 15 & 0.0035 & 0.0247 & 0.0436 & 0.0141 & 0.0047 \\
\hline 20 & 0.0047 & 0.0165 & 0.0518 & 0.0306 & 0.0071 \\
\hline \multicolumn{6}{|l|}{ Case $X$} \\
\hline 0 & 0 & 0 & 0 & 0 & 0 \\
\hline 5 & 0.0024 & 0.0071 & 0.0106 & 0.0106 & 0.0035 \\
\hline 10 & 0.0035 & 0.0082 & 0.0294 & 0.0283 & 0.0067 \\
\hline 15 & 0.0059 & 0.0082 & 0.0459 & 0.0448 & 0.0071 \\
\hline 20 & 0.0071 & 0.0071 & 0.0542 & 0.0495 & 0.0141 \\
\hline \multicolumn{6}{|l|}{ Case XI } \\
\hline 0 & 0 & 0 & 0 & 0 & 0 \\
\hline 5 & 0.0047 & 0.0059 & 0.0118 & 0.0130 & 0.0071 \\
\hline 10 & 0.0094 & 0.0094 & 0.0306 & 0.0342 & 0.0094 \\
\hline 15 & 0.0106 & 0.0118 & 0.0483 & 0.0506 & 0.0118 \\
\hline 20 & 0.0141 & 0.0153 & 0.0130 & 0.0683 & 0.0612 \\
\hline
\end{tabular}

Table 5: Angle of inclination and volume flux for case XI when $\theta=70^{\circ}$

\begin{tabular}{cc}
\hline $\begin{array}{c}\text { Angle of inclination } \alpha \\
(\mathrm{deg})\end{array}$ & $\begin{array}{c}\text { Volume flux } \\
\mathrm{q} \times 10^{-1}\left(\mathrm{~ms}^{-1}\right)\end{array}$ \\
\hline 0 & 0 \\
5 & 0.0130 \\
10 & 0.0342 \\
15 & 0.0506 \\
20 & 0.0683 \\
\hline
\end{tabular}


Table 6: Volume flux for various outlet for case $\mathrm{XI}, \propto=20^{\circ}$ porosity difference and $\Phi_{d}=0.083(\mathrm{AB})$

\begin{tabular}{cc}
\hline $\begin{array}{c}\text { Outlet } \\
\theta(\mathrm{deg})\end{array}$ & $\begin{array}{c}\text { Volume flux } \\
\mathrm{q} \times 10^{-1}\left(\mathrm{~ms}^{-1}\right)\end{array}$ \\
\hline 0 & 0.0047 \\
20 & 0.0165 \\
50 & 0.0518 \\
70 & 0.0306 \\
90 & 0.0071 \\
\hline
\end{tabular}

Table 7: Volume flux for various outlet for case XI porosity difference. $\alpha=20^{\circ}$ and $\Phi_{d}=0.114$ (AC)

\begin{tabular}{lcc}
\hline & $\begin{array}{c}\text { Outlet angle } \\
\theta(\mathrm{deg})\end{array}$ & $\begin{array}{c}\text { Volume flux } \\
\mathrm{q} \times 10^{-1}\left(\mathrm{~ms}^{-1}\right)\end{array}$ \\
\hline 0 & & 0.0071 \\
20 & & 0.0071 \\
50 & & 0.0542 \\
70 & & 0.0495 \\
90 & & 0.0141 \\
\hline
\end{tabular}

Table 8: Volume flux for various outlet for case XI. $\alpha=20^{0}$, porosity difference and $\Phi_{d}=0.114$ (AD)

\begin{tabular}{cc}
\hline $\begin{array}{c}\text { Angle of outlet } \\
\theta(\mathrm{deg})\end{array}$ & $\begin{array}{c}\text { Volume flux } \\
\mathrm{q} \times 10^{-1}\left(\mathrm{~ms}^{-1}\right)\end{array}$ \\
\hline 0 & 0.0141 \\
20 & 0.0153 \\
50 & 0.0130 \\
70 & 0.0683 \\
90 & 0.0612 \\
\hline
\end{tabular}

Table 9: Differences in porosity, $\Phi_{d}$ and optimum volume flux for case IX, $\mathrm{X}$ and $\mathrm{Xi}$

\begin{tabular}{cc}
\hline $\begin{array}{c}\text { Angle of outlet } \\
\theta(\mathrm{deg})\end{array}$ & $\begin{array}{c}\text { Volume flux } \\
\mathrm{q} \times 10^{-1}\left(\mathrm{~ms}^{-1}\right)\end{array}$ \\
\hline 0 & 0.0141 \\
50 & 0.0153 \\
70 & 0.0130 \\
90 & 0.0683 \\
\end{tabular}

Table 10:Volume flux at various angle of outlet with porosity difference $\left(\alpha=20^{\circ}\right)$

\begin{tabular}{|c|c|c|c|}
\hline $\begin{array}{c}\text { Angle of outlet } \\
\text { (degree) }\end{array}$ & $\begin{array}{l}\overrightarrow{A B}, \phi_{\mathrm{d}}=0.083 \\
\mathrm{q} \times 10^{-1}\left(\mathrm{~ms}^{-1}\right)\end{array}$ & $\begin{array}{l}\overrightarrow{A C}, \phi_{\mathrm{d}}=0.114 \\
\mathrm{q} \times 10^{-1}\left(\mathrm{~ms}^{-1}\right)\end{array}$ & $\begin{array}{l}\overrightarrow{A D}, \phi_{\mathrm{d}}=0.170 \\
\mathrm{q} \times 10^{-1}\left(\mathrm{~ms}^{-1}\right)\end{array}$ \\
\hline 0 & 0.0047 & 0.0071 & 0.0141 \\
\hline 20 & 0.0165 & 0.0071 & 0.0153 \\
\hline 50 & $0.0518^{*}$ & $0.0542^{*}$ & 0.0130 \\
\hline 70 & $0.0506^{*}$ & $0.0495^{*}$ & $0.0683^{*}$ \\
\hline 90 & 0.0071 & 0.0141 & $0.0612^{*}$ \\
\hline
\end{tabular}

${ }^{*}$ Relatively higher volume flux in each case

Table 11: Volume flux at various angle of outlet with porosity difference $\left(\alpha=20^{\circ}\right)$

\begin{tabular}{cccc}
\hline $\begin{array}{c}\text { Angle of outlet } \\
\text { (degree) }\end{array}$ & $\theta$ & $\overrightarrow{B A}, \phi_{\mathrm{d}}=0.083$ & $\overrightarrow{C A}, \phi_{\mathrm{d}}=0.114$ \\
$\mathrm{q} \times 10^{-1}\left(\mathrm{~ms}^{-1}\right)$ & $\mathrm{q} \times 10^{-1}\left(\mathrm{~ms}^{-1}\right)$ & $\begin{array}{c}\overrightarrow{D A}, \phi_{\mathrm{d}}=0.170 \\
\mathrm{q} \times 10^{-1}\left(\mathrm{~ms}^{-1}\right)\end{array}$ \\
\hline 0 & $0.1142^{*}$ & $0.1543^{*}$ & $0.1790^{*}$ \\
20 & $0.1095^{*}$ & $0.1272^{*}$ & $0.1398^{*}$ \\
50 & 0.0448 & 0.0730 & 0.0836 \\
70 & 0.0247 & 0.0306 & 0.0836 \\
90 & 0 & 0 & 0
\end{tabular}




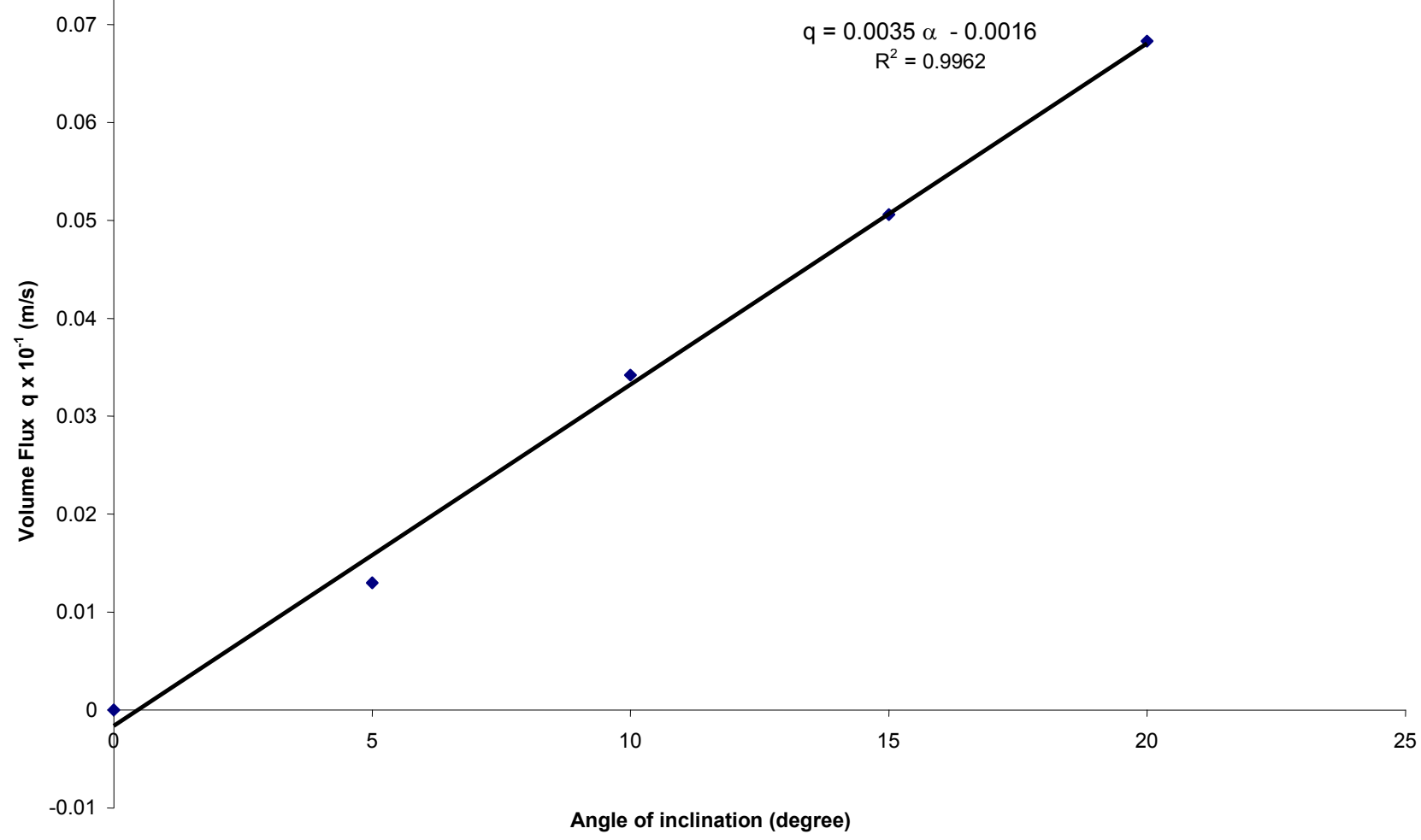

Fig. 1: Volume flux against Angle of inclination 


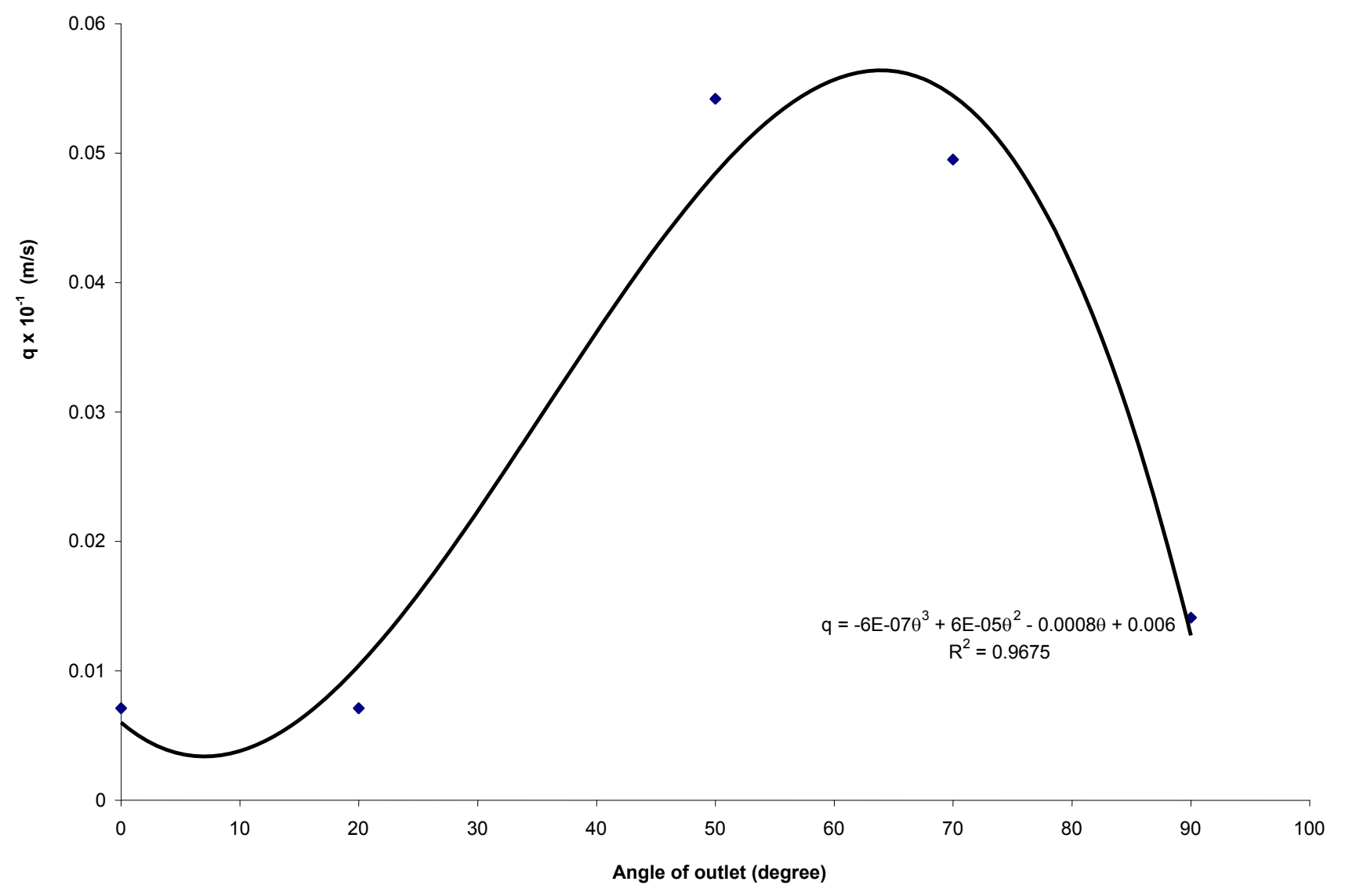

Fig. 3: Volume flux against Angle of outlet

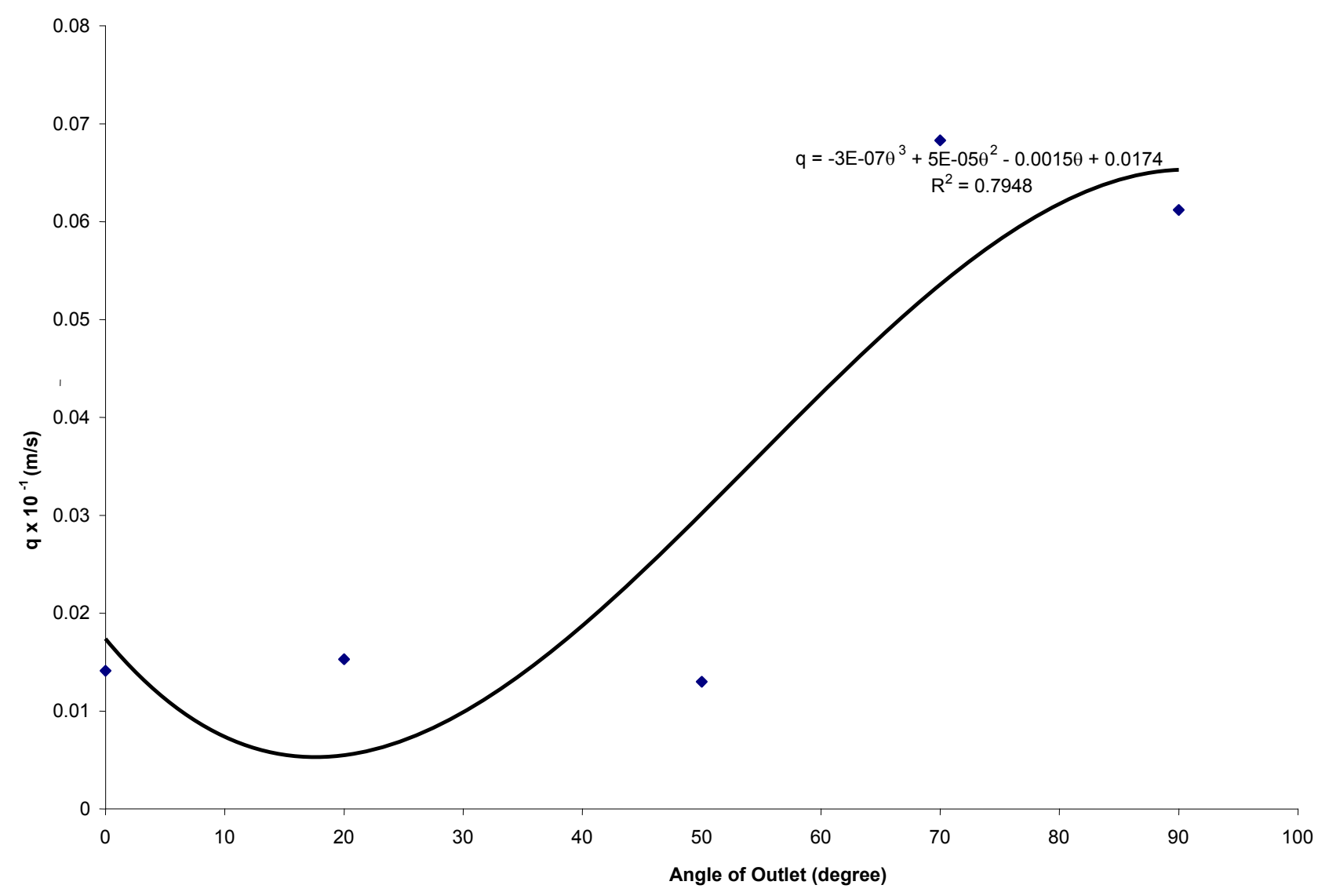

Fig. 4: Volume flux against Angle of outlet 
0.2

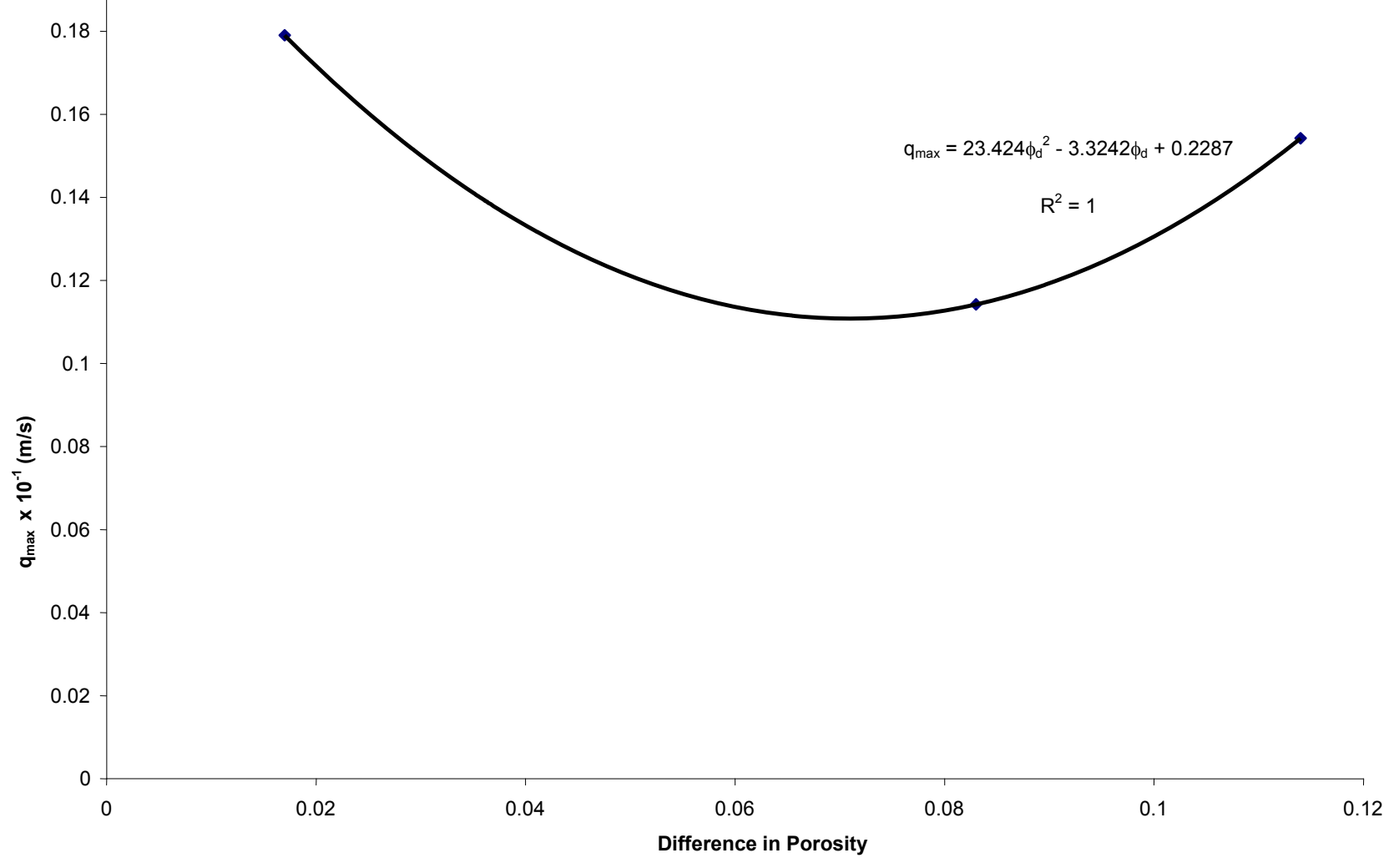

Fig. 5: Optimum volume flux against Difference in Porosity

\section{RESULTS AND DISCUSSION}

Fig. 1 shows that volume flux is related with angle of inclination linearly, that is volume flux increases with increasing angle of inclination, with relation $q=0.0035 \alpha-0.0016$

Fig. 2 shows that when fluid flows a lower porous medium $A$ to a higher porous medium $B$ with porosity difference $\phi_{\mathrm{d}}=0.083$, the volume flux is related with angle of outlet from the normal with polynomial equation of order 3 , with correction coefficient 0.89 . The equation is $q=-2 E-070 \theta^{3}+1 E-05 \theta^{2}+0.0008 \theta+$ 0.003

Fig 3 shows that when fluid flow a lower porous medium $A$ to a higher porous medium $C$ with porosity difference $\phi_{d}=0.114$, the volume flux is related with angle of outlet from the normal with polynomial equation of order 3 , with correlation coefficient 0.97 . The equation of the relation is $q=-6 E-07 \theta^{3}+6 E-$ $05 \theta^{2}-0.008 \theta+0.006$

Fig. 4 shows that when fluid flows from a lower porous medium $A$ to a higher porous medium $D$ with porosity difference $\phi_{\mathrm{d}}=0.170$, the volume flux is related with angle of outlet from the normal with polynomial equation of order 3 with correlation coefficient 0.8 . The equation of the relation is $q=-3 E$ $07 \theta^{3}+5 E-05 \theta^{2}-0.0015 \theta+0.0174$

Fig.5 shows that when fluid flows from a lower porous medium to a higher porous medium, the optimum volume flux obtained is relented with difference in porosity $\phi_{d}$ with polynomial equation of order 2 , with equation $q_{\max }=23.424 \phi_{d}^{2}-3.324 \phi_{d}+0.2287$

Table 1 presents the porosity and permeability for four samples A, B, C and D. The samples porosities ranged from 0.250 to 0.420 with the sample $D$ has the highest value and sample $A$ with lowest value. The permeability ranged from $0.47 \times 10^{-11} \mathrm{~m}^{2}$ for sample $A$ to $3.23 \times 10^{-11} \mathrm{~m}^{2}$ for sample $D$.

Table 2, presents the volume of water discharged from outlet pipes at various cases when the experimental set up was titled at different angles, that is angle of inclination. The volume of water discharged was not linearly increased across the range of angle of inclination for all outlet pipes. This is expedient from case I. However, it was linearly increased across the range for case II to case XI. The volume of water discharged recorded was zero for outlet 5 in all cases. The volume of water discharged was ranged from $0 \mathrm{ml}$ to $88.0 \mathrm{ml}$ from outlet 1 case I, 0 to $15.0 \mathrm{~mL}$ from outlet 1 in case II, 0 to $24.0 \mathrm{~mL}$ in case III, 0 to $42.4 \mathrm{~mL}$ from outlet 1 in case IV, 0 to $52.0 \mathrm{~mL}$ in case $\mathrm{V}, 0$ to $19.4 \mathrm{~mL}$ from outlet 1 in case $\mathrm{VI}, 0$ to $26.2 \mathrm{~mL}$ from outlet 1 in case $\mathrm{VII}$, 0 to $30.4 \mathrm{~mL}$ from outlet 1 in case VIII, 0 to $8.8 \mathrm{~mL}$ from outlet 3 in case IX, 0 to $9.2 \mathrm{~mL}$ from outlet 3 in case $X$ and 0 to $11.6 \mathrm{~mL}$ from outlet 4 in case XII. Also it shows from the table that the optimum or highest total volume was recorded in all cases at angle of inclination $20^{\circ}$ with value of $187.6 \mathrm{~mL}$ highest in case $1,124.4 \mathrm{~mL}$ in case $V$, $108 \mathrm{~mL}$ in case IV, $74.4 \mathrm{~mL}$ in case VIII $70.6 \mathrm{~mL}$ in case III, $65.4 \mathrm{~mL}$ in case VII, $49.8 \mathrm{~mL}$ in case $\mathrm{VI}, 33.4 \mathrm{~mL}$ in case II, $29.2 \mathrm{~mL}$ in case $X I I, 22.4 \mathrm{~mL}$ in case $X$ and $18.8 \mathrm{~mL}$ of in case IX.. 
Table 3 presents the volumetric flow rate $Q$ in various cases at different angles of inclination. It was computed directly from the values of volume discharged by dividing it by 60 secs, which in the total time taken for water to be discharged in each case. It was observed that the volumetric flow rate increases with increasing in angle of inclination in all cases except in outlet 3 and 4 for case I. Also, the volumetric flow rate was observed to be decreases with increasing in angle of outlet from the normal except in three different cases; in case IX, the highest volumetric flow rate was observed to be 0.1467 $\times 10^{-6} \mathrm{~m}^{3} \mathrm{~s}^{-1}$ at outlet 3 , in case $X$, the highest volumetric flow rate was observed to be $0.1533 \times 10^{-6} \mathrm{~m}^{3} \mathrm{~s}^{-1}$ at outlet 3 and in case XI it was $0.1933 \times 10^{-6} \mathrm{~m}^{3} \mathrm{~s}^{-1}$ at outlet 4 .

Table 4, presents the volume flux or specific discharge $\mathrm{q}$ in various cases at different angles of inclination. It was computed from the value of volumetric flow rate $Q$ in table 3 . The volume flux increases with increasing in angle of inclination across the range. However in outlet 3 and 4 for case I, the volume flux started decreasing from angle of inclination $15^{\circ}$. As it was recorded in table 3 , volume flux also decreases with increasing in angle of outlet from the normal except in cases IX, $X$ and $X I$ with highest volume flux of $0.0518 \times 10^{-1} \mathrm{~ms}^{-1}, 0.0542 \times 10^{-1} \mathrm{~ms}^{-1}$ and $0.0683 \times 10^{-1} \mathrm{~ms}^{-1}$ at outlet 3,3 and 4 respectively.

The results in table 2 and 3 for cases II to $V$ show that both the total volume of water discharged and volumetric flow rate increases with increasing in porosity, which is in order with Darcy's law and other recent works which indicated that volumetric flow rate increase with increasing porosity. This is also expedient from table 1 above. The highest total volume was recorded in case I because there was no material in the pipe to serve as impedance for the freely flow of the water. In addition, the highest total volume was recorded in angle $20^{\circ}$ of inclination. This was so because angle of inclination can be likened to hydraulic gradient, which influences the rate of fluid flow. According to Darcy's law, the velocity of flow is proportional to the hydraulic gradient. Thus, it is expected that the volume of discharge, volumetric flow rate and volume flux should be increased whenever the angle of inclination is increased. Zero volume of discharge, volumetric flow rate and volume flux was also in order because zero angle of inclination indicates hydrostatic angle or zero hydraulic gradient at which no flow is expected through the medium.

The results of the experiment as recorded in 3 revealed that three cases where highest values of both volumetric flow rate and volume flux were recorded at other outlets apart from outlet 1 was when fluid flows from a low porous medium to a higher porous medium, that is cases IX, X and XI. This is in line with Cedergreen's result, which states that if the fluid flows from a material of low permeability into one of higher permeability, it deflects as soon as possible into the material of higher permeability. In another work by Eagleman and Jamison and it was stated that in an arrangement of soil layers when soil of low permeability overlying a more permeable soil, the volumetric flow rate, volume discharged as well as volume flux should be lower than when it is arranged otherwise. This was found to be true in this work because the similar arrangement of soil samples as in case $\mathrm{IX}, \mathrm{X}$ and $\mathrm{XI}$ and they have lower total volume discharged when compared with cases VI, VII and VIII. However the option of soil samples in cases IX, X and XI provided the better arrangement in which high volume flux and volumetric flow rate can be obtained produced at outlets with higher angles from the normal. Thus, these cases will serve better for which is the more suitable for deflection of fluid through the layers of porous media. Furthermore it was observed that the higher the difference in the porosity of the cross-section of the soils in which the fluid is flowing through greater the fluid discharge, volumetric flow rate volume flux and the possibility of deflecting the fluid at outlet with higher angles from the normal.

By comparing tables 10 and 11 , it is expedient that relatively higher volume flux were recorded at outlet of higher angles in each cases in table 10 (where the fluid flow through a medium of low porosity to that of higher porosity) which is an indication of more deflection of fluid from normal to higher outlet angles. However, relatively higher volume fluxes were recorded at outlets of lower angle (table 11) which is an indication of less deflection.

\section{CONCLUSION}

i) The volume discharged, volumetric flow rate and volume flux do not decrease with increasing angle of outlets from the normal in all cases.

ii) The angle of inclination does not have a significant effect on the deflection of fluid from the normal or linear direction, but volume flux increases linearly with increasing angle of inclination with relation $q=0.0035 \alpha-0.00016$ for the most suitable case with outlet of $70^{\circ}$ from the normal.

iii) The higher the difference in the porosity of the cross-section of the media in which the fluid flows through, the greater the volume flux. The optimum volume flux and porosity difference are related with polynomial equation of order 2 . The equation is $q_{\max }=23.424 \phi_{d}-3.324 \phi_{d}+0.2287$

iv) The most suitable arrangement of cross-section of soil for deflection of fluid to higher angle from normal is when fluid flows from a medium of lower porosity to that of higher porosity. In such arrangement, high volume flux will be recorded at outlets of higher angle from the normal, which is an indication of deflection.

\section{REFERENCES}

Barer, L. D. et al., 1972. Soil Physics (New York: John Willy and Sons Inc)

Brain Clerk and Robert Klemberg, 2002. Physics in oil exploitation. Physics world, pp: 48-49.

Breadhoeft J., 1996. When Pollution goes with flow. Physics World, pp: 48-49.

Casagrande A., 1937. Seepage through Dams. Reprinted from Journal of the New England Water Works Association. Harvard University Pub. 209. 
Cedergreen, H. R., 1976. Seepage, Drainage and Flow Nets. (New York: Willy Interscience Publication).

Domenico, P. A. and F. W. Schwartz, 2000. Physics and Chemical Hydrogeology (New York: John Willy and Sons. Inc)

Eagleman J. R. and V.C. Jamison, 1962. Proceeding of American Soil Science Society. 26, pp.519.

Frick T.C. and R.W. Tailor, 1978. Petroleum Production Handbook, 23,.

Ghildyal, B.P. and R.P. Tripathi, 1987. Soil Physics (Willey Eastern Ltd., New Delhi).

Jacob Bear and Verrujit Arnold, 1990. Modelling Ground Water Flow and Pollution. (Reidel Publishing Company).

Jacob Bear, 2001 Modelling ground water flow and contaminant transport. Technion-Israel Institute of Tech. Israel pp: 1-30.
Popoola, I.O., J. A. Adegoke and O. O. Alabi, 2008. Study of Permeability of Saturated Homogeneous and Heterogeneous Porous Media. Journal of Scientific and Industrial Studies, 6(2):31-39.

Seitinger, P. and H. Schindlbauer, 1994. The behaviour of Oil spill in soil and groundwater. Natural resources and development Institute of scientific cooperation, Tubingen, Germany. 40,.

Sherwani; J. K, 1980. Elements of water supply and waste water disposal. $2^{\text {nd }}$ Edition (John willey and sons Inc) pp.122.

Sowers, G.B. and G.F. Sower, 1970. Introductory Soil Mechanics and Foundation (New York: Macmillan publishing Co. Inc). 